Article

\title{
Forecasting the Unit Cost of a Product with Some Linear Fuzzy Collaborative Forecasting Models
}

\section{Toly Chen}

Department of Industrial Engineering and Systems Management, Feng Chia University, Taichung City, 407, Taiwan; E-Mail: tolychen@ms37.hinet.net

Received: 6 June 2012; in revised form: 7 September 2012 / Accepted: 17 September 2012 /

Published: 15 October 2012

\begin{abstract}
Forecasting the unit cost of every product type in a factory is an important task. However, it is not easy to deal with the uncertainty of the unit cost. Fuzzy collaborative forecasting is a very effective treatment of the uncertainty in the distributed environment. This paper presents some linear fuzzy collaborative forecasting models to predict the unit cost of a product. In these models, the experts' forecasts differ and therefore need to be aggregated through collaboration. According to the experimental results, the effectiveness of forecasting the unit cost was considerably improved through collaboration.
\end{abstract}

Keywords: fuzzy collaborative forecasting; unit cost

\section{Introduction}

Cost forecasting means different things at different stages of the product life cycle. In product design, the designer needs to know whether the product will be economically produced. After a product goes into mass production, forecasting the unit cost is the basis of financial and production planning activities. When a product enters the market, the follow-up customer service and maintenance costs must also be taken into account.

Accurately predicting the unit cost of each product type is a very important task in any factory. If the unit cost is less than expected, then the efforts and investment of cost reduction are not necessary. Conversely, if the unit cost is more than expected, then the profitability of the product will be over-estimated, resulting in the wrong investment and production decisions. However, forecasting the unit cost is not an easy task because of the uncertainty of the unit cost, mainly due to the cost of human operations in the production of products, which is sometimes unstable. In addition, there is not much relevant literature in the unit cost forecasting. On the other hand, several recent studies (e.g. [1-14]) 
showed that fuzzy collaborative forecasting has great potential for the prediction of processes with uncertainty, such as yield learning, changes in price, fluctuations in the cycle time, and others. For these reasons, the application of fuzzy collaborative forecasting methods to improve the performance of the unit cost forecasting is worth a try. Therefore, some fuzzy collaborative forecasting models are proposed in this study, in order to enhance the accuracy and precision of the unit cost forecast.

In the proposed methodology, the stakeholders are a group of domain experts, such as the product engineer, factory managers and accounting department staff. These experts apply fuzzy linear regression methods to predict the unit cost of a product. A fuzzy linear regression equation can be converted into a linear or nonlinear programming problem in a variety of ways. Furthermore, within the conversion process some parameters need a subject setting. As a result, forecasts obtained by the experts may be very different and therefore requires a collaborative mechanism to deal with the following issues:

(1) How to integrate these forecasts?

(2) How experts can refer to the forecasts of others to modify their own?

In response to this issue, the methods presented in this study are as follows:

(1) Some linear fuzzy regression models for the unit cost forecasting are proposed and compared.

(2) Development of dedicated software to pass the forecast of each expert to other experts for their reference. In the meantime, the software can integrate different forecasts using the hybrid fuzzy intersection and back propagation network approach.

(3) In reference to the forecasts of others, each expert subjectively modifies the parameters in the fuzzy linear regression method.

The objectives of this study are as follows:

(1) To enhance the accuracy of the unit cost forecast. In other words, the forecasts obtained must be very close to the actual values.

(2) To improve the precision of the unit cost forecasting. Namely, a very small range containing the actual value can be estimated.

(3) The application of an instance to compare the advantages and disadvantages of different linear fuzzy collaborative forecasting models.

The organization of this study is described as follow. Section 2 first reviews the literature related to fuzzy collaborative forecasting and the unit cost forecasting. The problems faced by the existing methods are also discussed. Then, in Section 3, some fuzzy collaborative forecasting models are proposed to predict the unit cost of a product. An example is given to illustrate the applicability of these models. Section 4 makes conclusions and suggests some directions for future research.

\section{Related Work}

Carnes [15] established a basic equation to calculate the unit cost of a wafer. Carnes also compared the long-term costs of ownership of two alternative machines, but these costs were not allocated to the two machines. Wood [16] defined the lowest cost of all operations on the same machine as the minimum wafer cost. In Pfitzner et al.'s view, the recovery of wafers is becoming increasingly important in reducing the unit cost along with the growth in size of a wafer [17]. 
Although there have been some literature about fuzzy collaborative intelligence and systems, but very few directly related to fuzzy collaborative forecasting. Shai and Reich [18,19] defined the concept of infused design as an approach for establishing effective collaboration between designers from different engineering fields. Büyüközkan and Vardaloglu [20,21] applied the fuzzy cognitive map method to the collaborative planning, forecasting and replenishment of a supply chain. The initial values of the concepts and the connection weights of the fuzzy cognitive map are dependent on the subjective belief of the expert and can be modified after collaboration. According to Poler et al. [22], the comparison of collaboration methods and the proposing of software tools, especially as regards forecasting methods for collaborative forecasting, are still lacking. Pedrycz and Rai [14] discussed the problem of collaborative data analysis by a group of agents having access to different parts of data and exchanging findings through their collaboration. A two-phase optimization procedure was established, so that the results of communication can be embedded into the local optimization results. In recent years, Chen [6] used a hybrid fuzzy linear regression-back propagation network approach to predict the efficient cost per unit of a semiconductor product. This method first gathered a group of experts in the field. Each expert then used a fuzzy linear regression equation to predict the future unit cost. The result is a fuzzy value, and can be regarded as a non-symmetric interval forecast. A crisp forecast rarely equal to the actual value. In contrast, a fuzzy forecast can contain the actual value. The fuzzy forecasts obtained by different experts are aggregated using a fuzzy intersection, resulting in a polygon-shaped fuzzy number, which can be defuzzified using a back propagation network. Chen [4] considered the case in which each expert has only partial access to the data, and is not willing to share the raw data he/she owns. The forecasting results by an expert are conveyed to other experts for the modification of their settings, so that the actual values will be contained in the fuzzy forecasts after collaboration. All fuzzy collaborative intelligence methods seek consensus of results. In this field, Ostrosi et al. [23] defined the concept of consensus as the overlapping of design clusters of different perspectives. Similarly, Chen [2] defined the concept of partial consensus as the intersection of the views of some experts. Cheikhrouhou et al. [24] thought that collaboration is necessary because of the unexpected events that may occur in the future demand.

In short, the existing approaches have the following problems:

(1) The unit cost forecasted by the existing methods may be lower than the actual value, resulting in over-estimated profits if the financial plan is based on the forecasts.

(2) For precision in the unit cost forecasting, the narrowest scope containing the actual value is required; however, this has rarely been discussed.

(3) The peak and average unit costs are forecasted separately, which is problematic because it is possible that the forecast becomes invalid in the sense that the average value may be higher than the peak value [10].

(4) The existing fuzzy linear regression-back propagation network methods selected particular fuzzy linear regression methods, but did not explain the reasons or compared with other fuzzy linear regression methods. 


\section{Methodology}

The parameters used in the proposed methodology are defined in advance.

(1) $b$ : learning constant.

(2) $a_{t}$ : normalized unit cost at period $t$.

(3) $c_{t}$ : actual unit cost at period $t$.

(4) $\tilde{c}_{t}$ : fuzzy unit cost forecast at period $t . \tilde{c}_{t}=\left(c_{t 1}, c_{t 2}, c_{t 3}\right)$ if it is represented with a triangular fuzzy number .

(5) $C$ : unit wafer cost.

(6) $G$ : gross die.

(7) $r(t)$ : homoscedastical, serially non-correlated error term.

(8) $t$ : period.

(9) $T$ : current period.

(10) $Y_{t}$ : yield at period $t$.

(11) $Y_{0}$ : asymptotic/final yield.

Prior to predict the unit cost of a product, we emphasize at the outset that the reduction in the unit cost follows a learning process, which is the assumption of this study.

\subsection{Fuzzy Linear Regression Methods for Forecasting the Unit Cost}

According to Gruber [25], the yield of a product follows a learning process:

$$
Y_{t}=Y_{0} e^{-b / t+r(t)}
$$

The unit cost can be calculated as

$$
c_{t}=C /\left(Y_{t} \cdot G\right)=C /\left(Y_{0} e^{-b / t+r(t)} \cdot G\right)=C / Y_{0} G e^{b / t-r(t)}
$$

Obviously, the change in the unti cost is also a learning process, not a usual time-series. After converting to logarithms,

$$
\ln c_{t}=\ln C-\ln Y_{0}-\ln G+b / t-r(t)=a+b / t-r(t)
$$

where $a=\ln C-\ln Y_{0}-\ln G$. To consider the uncertainty in the unit cost, parameters in equation (3) are given in asymmetric triangular fuzzy numbers as follows [26-29]:

$$
\begin{gathered}
\tilde{a}=\left(a_{1}, a_{2}, a_{3}\right) \\
\tilde{b}=\left(\begin{array}{ll}
b_{1}, & b_{2}, \\
b_{3}
\end{array}\right)
\end{gathered}
$$

Therefore,

$$
\ln \tilde{c}_{t} \cong\left(\ln c_{t 1}, \ln c_{t 2}, \ln c_{t 3}\right)=\tilde{a}(+) \tilde{b} / t-r(t)=\left(a_{1}+b_{1} / t, a_{2}+b_{2} / t, a_{3}+b_{3} / t\right)-r(t)
$$

where (+) represents fuzzy addition. Equation (6) is obviously a fuzzy linear regression equation.

A fuzzy linear regression equation can be fitted in various ways. For example, in Tanaka and Watada [30], a linear programming problem is solved to minimize the fuzziness: 


$$
\operatorname{Min} Z=\sum_{t=1}^{T}\left(\ln c_{t 3}-\ln c_{t 1}\right)
$$

subject to

$$
\begin{gathered}
\ln c_{t} \geq \ln c_{t 1}+s\left(\ln c_{t 2}-\ln c_{t 1}\right) \\
\ln c_{t} \leq \ln c_{t 3}+s\left(\ln c_{t 2}-\ln c_{t 3}\right) \\
c_{t 1}=a_{1}+b_{1} / t \\
c_{t 2}=a_{2}+b_{2} / t \\
c_{t 3}=a_{3}+b_{3} / t \\
0 \leq a_{1} \leq a_{2} \leq a_{3} \\
0 \leq b_{1} \leq b_{2} \leq b_{3} \\
t=1 \sim T
\end{gathered}
$$

where $s$ is the satisfaction level. For the training data, the actual values will fall within the ranges of the fuzzy forecasts. Clearly, the higher value of $s$ leads to wider fuzzy forecasts. This model is indicated with $\mathrm{WT}(s)$.

The second method for fitting a fuzzy linear regression equation is Peters' method [31], in which the following linear programming problem is solved, aimed at the maximization of the average satisfaction level:

$$
\operatorname{Max} Z=\bar{s}
$$

subject to

$$
\begin{gathered}
\sum_{t=1}^{T}\left(\ln c_{t 3}-\ln c_{t 1}\right) \leq T \cdot d \\
\ln c_{t} \geq \ln c_{t 1}+s_{t}\left(\ln c_{t 2}-\ln c_{t 1}\right) \\
\ln c_{t} \leq \ln c_{t 3}+s_{t}\left(\ln c_{t 2}-\ln c_{t 3}\right) \\
\sum_{t=1}^{T} s_{t} \\
T \\
c_{t 1}=a_{1}+b_{1} / t \\
c_{t 2}=a_{2}+b_{2} / t \\
c_{t 3}=a_{3}+b_{3} / t \\
0 \leq a_{1} \leq a_{2} \leq a_{3} \\
0 \leq b_{1} \leq b_{2} \leq b_{3} \\
0 \leq s_{t} \leq 1 \\
t=1 \sim T
\end{gathered}
$$


where $d$ is the required range of a fuzzy forecast. Clearly, a larger value of $d$ results in a higher average satisfaction level. This model is indicated with Peters $(d)$.

The third method for fitting a fuzzy linear regression equation is Donoso's quadratic non-possibilistic method [32], in which the quadratic error for both the central tendency and each one of the spreads is minimized:

$$
\operatorname{Min} Z=k_{1} \sum_{t=1}^{T}\left(c_{t}-c_{t 2}\right)^{2}+k_{2} \sum_{t=1}^{T}\left(\left(c_{t}-\ln c_{t 3}\right)^{2}+\left(c_{t}-\ln c_{t 1}\right)^{2}\right)
$$

subject to

$$
\begin{gathered}
\ln c_{t} \geq \ln c_{t 1}+s\left(\ln c_{t 2}-\ln c_{t 1}\right) \\
\ln c_{t} \leq \ln c_{t 3}+s\left(\ln c_{t 2}-\ln c_{t 3}\right) \\
c_{t 1}=a_{1}+b_{1} / t \\
c_{t 2}=a_{2}+b_{2} / t \\
c_{t 3}=a_{3}+b_{3} / t \\
0 \leq a_{1} \leq a_{2} \leq a_{3} \\
0 \leq b_{1} \leq b_{2} \leq b_{3} \\
t=1 \sim T
\end{gathered}
$$

where $k_{1}$ and $k_{2}$ belong to [0 1], and add up to 1 . This model is indicated with $\operatorname{Donoso}\left(k_{1}, k_{2}, s\right)$.

The fourth method for fitting a fuzzy linear regression equation is Chen and Lin's nonlinear programming method [8], which changes the objectives and constraints in the two linear programming models into nonlinear:

Model I

$$
\operatorname{Min} Z=\sum_{t=1}^{T}\left(\ln c_{t 3}-\ln c_{t 1}\right)^{o}
$$

subject to

$$
\begin{gathered}
\ln c_{t} \geq \ln c_{t 1}+s\left(\ln c_{t 2}-\ln c_{t 1}\right) \\
\ln c_{t} \leq \ln c_{t 3}+s\left(\ln c_{t 2}-\ln c_{t 3}\right) \\
c_{t 1}=a_{1}+b_{1} / t \\
c_{t 2}=a_{2}+b_{2} / t \\
c_{t 3}=a_{3}+b_{3} / t \\
0 \leq a_{1} \leq a_{2} \leq a_{3} \\
0 \leq b_{1} \leq b_{2} \leq b_{3} \\
t=1 \sim T
\end{gathered}
$$

Model II

$$
\operatorname{Max} Z=\bar{s}
$$

subject to 


$$
\begin{gathered}
\sum_{t=1}^{T}\left(\ln c_{t 3}-\ln c_{t 1}\right)^{o} \leq T \cdot d^{o} \\
\ln c_{t} \geq \ln c_{t 1}+s_{t}\left(\ln c_{t 2}-\ln c_{t 1}\right) \\
\ln c_{t} \leq \ln c_{t 3}+s_{t}\left(\ln c_{t 2}-\ln c_{t 3}\right) \\
\bar{s}=\sqrt[m]{\frac{\sum_{t=1}^{T} s_{t}^{m}}{T}} \\
c_{t 1}=a_{1}+b_{1} / t \\
c_{t 2}=a_{2}+b_{2} / t \\
c_{t 3}=a_{3}+b_{3} / t \\
0 \leq a_{1} \leq a_{2} \leq a_{3} \\
0 \leq b_{1} \leq b_{2} \leq b_{3} \\
0 \leq s_{t} \leq 1 \\
t=1 \sim T
\end{gathered}
$$

where $o$ reflects the sensitivity to the uncertainty of the fuzzy forecast; $o$ ranges from 0 (not sensitive) to $\infty$ (extremely sensitive); $s$ indicates the required satisfaction level; $0 \leq s \leq 1$; $d$ is the desired range of every fuzzy forecast; $0 \leq d ; m$ represents the relative importance of the outliers in fitting the fuzzy linear regression equation; $m \in Z^{+}$. When $m=1$, the relative importance of the outliers is the highest and is equal to that of the non-outliers. $o$ should be set within $\left[\begin{array}{ll}0 & 1\end{array}\right]$ if the variation in the variable is less than 1. Otherwise, it should be greater than 1 . The two nonlinear programming models are indicated with $\operatorname{CL} 1(o, s)$ and CL2 $(o, d, m)$, respectively.

\subsection{Aggregation of Fuzzy Forecasts in Fuzzy Collaborative Forecasting}

A mechanism is required to combine the fuzzy forecasts. The aggregation mechanism consists of two steps. In the first step, fuzzy intersection is applied to aggregate the fuzzy forecasts into a polygon-shaped fuzzy number, in order to improve the precision of forecasting. Every fuzzy forecast contains the actual value. As a result, the intersection of the fuzzy forecasts also contains the actual value. Besides, the intersection has a narrower range than those of the original regions. Therefore, the forecasting precision measured in terms of the average range is indeed improved after intersection, which is one of the basic mechanisms of fuzzy collaborative forecasting. Fuzzy intersection combines $n$ fuzzy forecasts in the following manner:

$$
\mu_{I\left(\tilde{c}_{t}(1), \tilde{c}_{t}(2) \quad \ldots, \tilde{c}_{t}(L)\right)}(x)=\min \left(\mu_{\widetilde{c}_{t}(1)}(x), \quad \mu_{\widetilde{c}_{t}(2)}(x), \quad \ldots, \quad \mu_{\widetilde{c}_{t}(L)}(x)\right)
$$

where $I\left(\tilde{c}_{t}(1), \quad \tilde{c}_{t}(2), \ldots, \tilde{c}_{t}(L)\right)$ indicates the result of obtaining the fuzzy intersection of the fuzzy forecasts by $L$ experts. If these fuzzy forecasts are approximated with triangular fuzzy numbers, then the fuzzy intersection is a polygon-shaped fuzzy number (see Figure 1). 
Figure 1. The fuzzy intersection of two triangular fuzzy numbers.

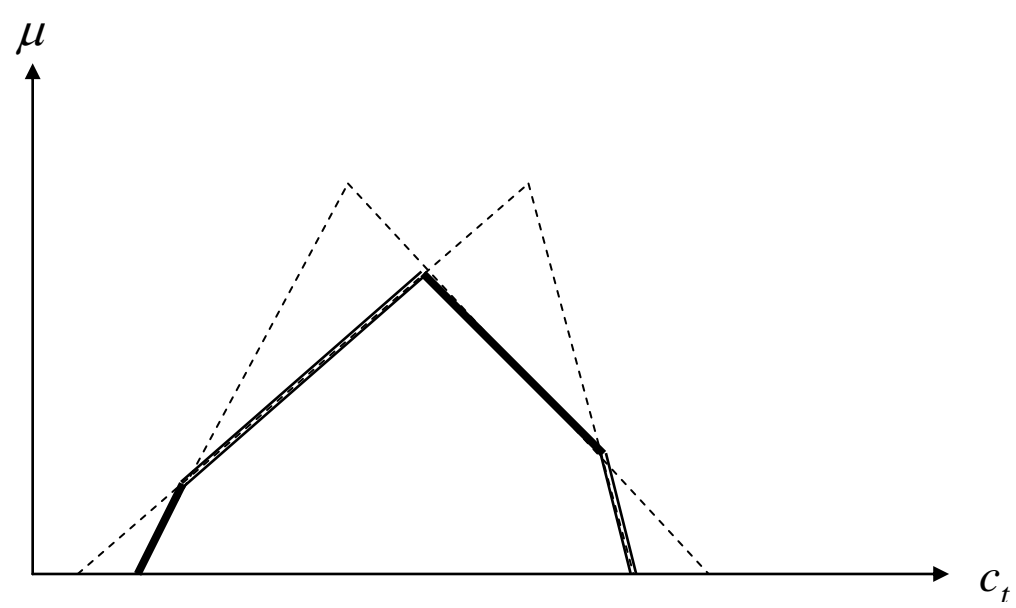

The result of this step is a polygon-shaped fuzzy number that specifies the narrowest range of the fuzzy forecast. However, in practical applications a crisp forecast is usually required. Therefore, a crisp forecast has to be generated from the polygon-shaped fuzzy number. For this purpose, a variety of defuzzification methods are applicable [33]. Once the defuzzified value is obtained it is compared with the actual value to evaluate the accuracy. However, among the existing defuzzification methods, no one method is better than all the other methods in every case. In addition, the most suitable defuzzification method for a fuzzy variable is often chosen from the existing methods, and thus the optimality of the chosen method cannot be guaranteed. Also, the shape of the polygon-shaped fuzzy number is special. These phenomena are reasons for proposing a tailored defuzzification method. In this study, a back propagation network is applied, because theoretically a well-trained back propagation network (without being stuck in a local minima) with a good selected topology can successfully map any complex distribution.

The configuration of the back propagation network used is established as follows:

(1) Inputs: $2 m$ parameters corresponding to the $m$ corners of the polygon-shaped fuzzy number and the membership function values of these corners. The reason is that simple-aggregation results in a convex domain and each point in it can be expressed with the combination of corners. The fuzzy intersection of $L$ fuzzy forecasts will have at most $2 \cdot\left(2^{L}+2\right)$ corners. All input parameters have to be normalized into a range narrower than [0 1] before they are fed into the network.

(2) Single hidden layer: Generally one or two hidden layers are more beneficial for the convergence property of the back propagation network.

(3) The number of neurons in the hidden layer is chosen from 1 4m according to a preliminary analysis, considering both effectiveness (forecasting accuracy) and efficiency (execution time).

(4) Output: the crisp forecast.

(5) Network learning rule: Delta rule.

(6) Network learning algorithms: There are many advanced algorithms for training a back propagation network, e.g. the Fletcher-Reeves algorithm, the Broydon-Fletcher-Goldfarb-Shanno algorithm, the Levenberg-Marquardt algorithm, and the Bayesian regularization method [34]. In this study, the Levenberg-Marquardt algorithm is applied. 
(7) Number of epochs per replication: 10,000.

(8) Activation function: Log-sigmoid function.

(9) Number of initial conditions/replications: Because the performance of a back propagation network is sensitive to the initial condition, the training process will be repeated many times with different initial conditions that are randomly generated. Among the results, the best one is chosen for the subsequent analyses.

The Levenberg-Marquardt algorithm was designed for training with second-order speed without having to compute the Hessian matrix. It uses approximation and updates the network parameters in a Newton-like way. When training a back propagation network, the Hessian matrix can be approximated as:

$$
H=J^{T} J
$$

and the gradient can be computed as:

$$
g=J^{T} e
$$

where $J$ is the Jacobian matrix containing the first derivatives of the network errors with respect to the weights and biases; $e$ is the vector of the network errors. The Levenberg-Marquardt algorithm uses this approximation and updates the network parameters in a Newton-like way:

$$
x_{e p+1}=x_{e p}-\left[J^{T} J+\mu I\right]^{-1} J^{T} e
$$

where $e p$ is the epoch number. Newton's method is faster and more accurate near an error minimum, so the Levenberg-Marquardt algorithm's purpose is to move as quickly as possible to Newton's method. Thus, $\mu$ decreases after each successful step and increases only when a tentative step will increase the performance function. Consequently, the performance function is always reduced after each epoch.

\subsection{Performance Evaluation in Fuzzy Collaborative Forecasting}

Some performance measures of fuzzy collaborative forecasting are defined as follows.

Definition 1. $F(p)$ is a fuzzy forecasting method with parameter $p$. The fuzzy forecast at period $t$ using $F(p)$ is indicated with $F_{t}(p)=\left(F_{t 1}(p), F_{t 2}(p), F_{t 3}(p)\right)$. The precision and accuracy of $F(p)$ are indicated with $\operatorname{Prec}(F(p))$ and $\operatorname{Accur}(F(p))$, respectively. Some of the common functions for $\operatorname{Prec}(F(p))$ and $\operatorname{Accur}(F(p))$ are described below:

(1) The average range (AR):

$$
\operatorname{Prec}_{\mathrm{AR}}(F(p))=\sum_{t=1}^{T}\left(F_{t 3}(p)-F_{t 1}(p)\right) / T
$$

(1) Mean absolute error (MAE):

$$
\operatorname{Accu}_{\mathrm{MAE}}(F(p))=\sum_{t=1}^{T}\left|D\left(F_{t}(p)\right)-a_{t}\right| / T
$$

where $D()$ is the defuzzification function; $a_{t}$ is the actual value at period $t$.

Mean absolute percentage error (MAPE): 


$$
\operatorname{Accu}_{\mathrm{MAPE}}(F(p))=\sum_{t=1}^{T} \frac{\left|D\left(F_{t}(p)\right)-a_{t}\right| / a_{t}}{T}
$$

(2) Root mean squared error (RMSE):

$$
\operatorname{Accu}_{\mathrm{RMSE}}(F(p))=\sqrt{\sum_{t=1}^{T} \frac{\left(D\left(F_{t}(p)\right)-a_{t}\right)^{2}}{T}}
$$

All of these performance indicators are as small as possible.

Definition 2. $F C F(F, G)$ is a fuzzy collaborative forecasting method on the basis of two forecasting methods $F$ and $G$. The quality of collaboration in the precision and accuracy are indicated with $Q o C p(F C F)$ and $Q o C a(F C F)$, respectively. Some of the common functions for $Q o C p(F C F)$ and $Q o C a(F C F)$ are described below:

(1) Maximum percentage improvement (MPI):

$$
\begin{gathered}
\operatorname{QoCp}_{\mathrm{MPI}}(\mathrm{FCF})=\operatorname{Max}\left(\frac{\operatorname{Prec}(F)-\operatorname{Prec}(F C F)}{\operatorname{Prec}(F)}, \frac{\operatorname{Prec}(G)-\operatorname{Prec}(F C F)}{\operatorname{Prec}(G)}\right) \cdot 100 \% \\
\operatorname{QoCa}_{\mathrm{MPI}}(\mathrm{FCF})=\operatorname{Max}\left(\frac{\operatorname{Accu}(F)-\operatorname{Accu}(F C F)}{\operatorname{Accu}(F)}, \frac{\operatorname{Accu}(G)-\operatorname{Accu}(F C F)}{\operatorname{Accu}(G)}\right) \cdot 100 \%
\end{gathered}
$$

(2) Average percentage improvement (API):

$$
\begin{gathered}
\operatorname{QoCp}_{\mathrm{API}}(\mathrm{FCF})=\left(\frac{\operatorname{Prec}(F)-\operatorname{Prec}(F C F)}{\operatorname{Prec}(F)}+\frac{\operatorname{Prec}(G)-\operatorname{Prec}(F C F)}{\operatorname{Prec}(G)}\right) / 2 \cdot 100 \% \\
\mathrm{QoCa}_{\mathrm{API}}(\mathrm{FCF})=\left(\frac{\operatorname{Accu}(F)-\operatorname{Accu}(F C F)}{\operatorname{Accu}(F)}+\frac{\operatorname{Accu}(G)-\operatorname{Accu}(F C F)}{\operatorname{Accu}(G)}\right) / 2 \cdot 100 \%
\end{gathered}
$$

These functions can easily be extended to involve more than two objects.

\subsection{Some Fuzzy Collaborative Forecasting Models for the Unit Cost Forecasting}

An example is given in Table 1. The data of the first 7 periods were used as training data, and the remaining data are left for testing.

Table 1. An example.

\begin{tabular}{cc}
\hline $\mathbf{t}$ & $\mathbf{c}_{\mathbf{t}}$ (US\$) \\
\hline 1 & 2.57 \\
2 & 1.61 \\
3 & 1.76 \\
4 & 1.28 \\
5 & 1.53 \\
6 & 1.19 \\
7 & 1.32 \\
8 & 1.32 \\
9 & 1.61 \\
10 & 1.32 \\
\hline
\end{tabular}


Some linear fuzzy collaboration forecasting models for used to predict the unit cost.

\section{Model 1. FCF $\left(W T\left(s_{1}\right), W T\left(s_{2}\right)\right)$}

In this model, the two objects use the same fuzzy linear regression method (WT $(s)$ ), but with different values of $s$ to predict the unit cost. In WT $(s)$, the most precise forecast is associated with the minimum value of $s$ that satisfies the constraints. In addition, the results when $s$ is large often contain the results when $s$ is relatively small, which makes it less effective for their collaboration. Nevertheless, the fuzzy collaborative forecasting method, to a certain extent, improves the precision of $\mathrm{WT}(s)$. In the previous example, assuming the $s$ values specified by the objects are 0.3 and 0.6 , respectively:

$$
\begin{aligned}
& \operatorname{Prec}_{\mathrm{AR}}(\mathrm{WT}(0.3))=0.56 \\
& \operatorname{Prec}_{\mathrm{AR}}(\mathrm{WT}(0.6))=1.14 \\
& \operatorname{Prec}_{\mathrm{AR}}(\mathrm{FCF}(\mathrm{WT}(0.3), \mathrm{WT}(0.6)))=0.53
\end{aligned}
$$

Therefore, the quality of collaboration with respect to the forecasting precision can be evaluated as

$$
\begin{aligned}
& Q o C p_{\mathrm{MPI}, \mathrm{AR}}(\mathrm{FCF}(\mathrm{WT}(0.3), \mathrm{WT}(0.6)))=\max ((1.14-0.53) / 1.14,(0.56-0.53) / 0.56)=54 \% . \\
& Q o C p_{\mathrm{API}, \mathrm{AR}}(\mathrm{FCF}(\mathrm{WT}(0.3), \mathrm{WT}(0.6)))=((1.14-0.53) / 1.14+(0.56-0.53) / 0.56) / 2=29 \% .
\end{aligned}
$$

In order to evaluate the forecasting accuracy, the forecasts by the two objects are defuzzified using the center of gravity (COG) method, and then are compared with the actual values:

$$
\begin{aligned}
& A c c u_{\mathrm{MAE}}(\mathrm{WT}(0.3))=0.16 \\
& A c c u_{\mathrm{MAE}}(\mathrm{WT}(0.6))=0.24 \\
& A c c u_{\mathrm{MAPE}}(\mathrm{WT}(0.3))=10 \% \\
& A c c u_{\mathrm{MAPE}}(\mathrm{WT}(0.6))=15 \% \\
& A c c u_{\mathrm{RMSE}}(\mathrm{WT}(0.3))=0.19 \\
& A c c u_{\mathrm{RMSE}}(\mathrm{WT}(0.6))=0.31
\end{aligned}
$$

while in the fuzzy collaborative forecasting method, the forecasts by the two objects are aggregated using the fuzzy intersection and back propagation network approach to generate a single crisp value:

$A c c u_{\mathrm{MAE}}(\mathrm{FCF}(\mathrm{WT}(0.3), \mathrm{WT}(0.6)))=0.06$

$A c c u_{\mathrm{MAPE}}(\mathrm{FCF}(\mathrm{WT}(0.3), \mathrm{WT}(0.6)))=4 \%$

$A c c u_{\mathrm{RMSE}}(\mathrm{FCF}(\mathrm{WT}(0.3), \mathrm{WT}(0.6)))=0.10$

Therefore, the quality of collaboration with respect tothe forecasting accuracy can be evaluated as

$Q o C a_{\text {MPI,MAE }}(\operatorname{FCF}(\mathrm{WT}(0.3), \mathrm{WT}(0.6)))=\max ((0.16-0.07) / 0.16,(0.24-0.07) / 0.24)=71 \%$.

$Q o C a_{\mathrm{API}, \mathrm{MAE}}(\mathrm{FCF}(\mathrm{WT}(0.3), \mathrm{WT}(0.6)))=((0.16-0.07) / 0.16+(0.24-0.07) / 0.24) / 2=64 \%$.

$Q o C a_{\text {MPI,MAPE }}(\operatorname{FCF}(\mathrm{WT}(0.3), \mathrm{WT}(0.6)))=\max ((10 \%-5 \%) / 10 \%,(15 \%-5 \%) / 15 \%)=67 \%$.

$Q o C a_{\text {API,MAPE }}(\mathrm{FCF}(\mathrm{WT}(0.3), \mathrm{WT}(0.6)))=((10 \%-5 \%) / 10 \%+(15 \%-5 \%) / 15 \%) / 2=58 \%$.

$Q o C a_{\mathrm{MPI}, \mathrm{RMSE}}(\mathrm{FCF}(\mathrm{WT}(0.3), \mathrm{WT}(0.6)))=\max ((0.19-0.15) / 0.19,(0.31-0.15) / 0.31)=52 \%$.

$Q o C a_{\mathrm{API}, \mathrm{RMSE}}(\mathrm{FCF}(\mathrm{WT}(0.3), \mathrm{WT}(0.6)))=((0.19-0.15) / 0.19+(0.31-0.15) / 0.31) / 2=36 \%$.

\section{Model 2. FCF(Peters $\left.\left(d_{1}\right), \operatorname{Peters}\left(d_{2}\right)\right)$}

In this model, both objects use Peters $(d)$, but with different $d$ values to predict the unit cost. In Peters $(d)$, the most precise forecast is associated with the minimum value of $d$ that satisfies the constraints. In addition, the results when $d$ is large often contain the results when $d$ is relatively small. As a result, the benefits of collaboration are not obvious. In the previous example, assuming the $d$ values specified by the objects are 0.3 and 0.5 , respectively. The forecasting performances of the two objects are evaluated as 


$$
\begin{aligned}
& \operatorname{Prec}_{\mathrm{AR}}(\operatorname{Peters}(0.3))=0.48 \\
& \operatorname{Prec}_{\mathrm{AR}}(\operatorname{Peters}(0.5))=0.68 \\
& \operatorname{Accu}_{\mathrm{MAE}}(\operatorname{Peters}(0.3))=0.16 \\
& A c c u_{\mathrm{MAE}}(\operatorname{Peters}(0.5))=0.20 \\
& A c c u_{\mathrm{MAPE}}(\operatorname{Peters}(0.3))=10 \% \\
& A c c u_{\mathrm{MAPE}}(\operatorname{Peters}(0.5))=12 \% \\
& A c c u_{\mathrm{RMSE}}(\operatorname{Peters}(0.3))=0.19 \\
& A c c u_{\mathrm{RMSE}}(\operatorname{Peters}(0.5))=0.25
\end{aligned}
$$

After collaboration, the forecasting precision and accuracy are both improved:

$\operatorname{Prec}_{\mathrm{AR}}(\mathrm{FCF}(\operatorname{Peters}(0.3)$, Peters $(0.5)))=0.48$

$A c c u_{\mathrm{MAE}}(\mathrm{FCF}(\operatorname{Peters}(0.3), \operatorname{Peters}(0.5)))=0.07$

$A c c u_{\text {MAPE }}(\mathrm{FCF}(\operatorname{Peters}(0.3)$, Peters $(0.5)))=6 \%$

$A c c u_{\mathrm{RMSE}}(\mathrm{FCF}(\operatorname{Peters}(0.3)$, Peters $(0.5)))=0.13$

The quality of collaboration in the two aspects can be evaluated as

$Q o C p_{\mathrm{MPI}, \mathrm{AR}}(\mathrm{FCF}(\operatorname{Peters}(0.3)$, Peters $(0.5)))=29 \%$.

$Q o C p_{\mathrm{API}, \mathrm{AR}}(\mathrm{FCF}(\operatorname{Peters}(0.3)$, Peters $(0.5)))=15 \%$.

and

$Q o C a_{\mathrm{MPI}, \mathrm{MAE}}(\mathrm{FCF}(\operatorname{Peters}(0.3)$, Peters $(0.5)))=65 \%$.

$Q o C a_{\mathrm{API}, \mathrm{MAE}}(\mathrm{FCF}(\operatorname{Peters}(0.3)$, Peters $(0.5)))=61 \%$.

$Q o C a_{\mathrm{MPI}, \mathrm{MAPE}}(\mathrm{FCF}(\operatorname{Peters}(0.3)$, Peters $(0.5)))=50 \%$.

$Q o C a_{\mathrm{API}, \mathrm{MAPE}}(\mathrm{FCF}(\operatorname{Peters}(0.3)$, Peters $(0.5)))=45 \%$.

$Q o C a_{\mathrm{MPI}, \mathrm{RMSE}}(\mathrm{FCF}(\operatorname{Peters}(0.3)$, Peters $(0.5)))=48 \%$.

$Q o C a_{\mathrm{API}, \mathrm{RMSE}}(\mathrm{FCF}(\operatorname{Peters}(0.3)$, Peters $(0.5)))=40 \%$.

respectively.

\section{Model 3. FCF(Donoso $\left.\left(k_{11}, k_{21}, s_{1}\right), \operatorname{Donoso}\left(k_{12}, k_{22}, s_{2}\right)\right)$}

In this model, both objects use $\operatorname{Donoso}\left(k_{1}, k_{2}, s\right)$, but with different parameter values to predict the unit cost. This method has more parameters that can be adjusted, so there is a greater degree of freedom, which provides a space for coordination. Assuming in the previous example, the parameter values specified by the two objects are

$$
\begin{aligned}
& \left(k_{11}, k_{21}, s_{1}\right)=(0.2,0.8,0.2) \\
& \left(k_{12}, k_{22}, s_{2}\right)=(0.7,0.3,0.3)
\end{aligned}
$$

Then their forecasting performances are

$\operatorname{Prec}_{\mathrm{AR}}(\operatorname{Donoso}(0.2,0.8,0.2))=0.48$

$\operatorname{Prec}_{\mathrm{AR}}(\operatorname{Donoso}(0.7,0.3,0.3))=0.57$

$\operatorname{Accu}_{\mathrm{MAE}}(\operatorname{Donoso}(0.2,0.8,0.2))=0.15$

$\operatorname{Accu}_{\mathrm{MAE}}(\operatorname{Donoso}(0.7,0.3,0.3))=0.14$

$\operatorname{Accu}_{\mathrm{MAPE}}(\operatorname{Donoso}(0.2,0.8,0.2))=9 \%$

$\operatorname{Accu}_{\mathrm{MAPE}}(\operatorname{Donoso}(0.7,0.3,0.3))=9 \%$

$\operatorname{Accu}_{\mathrm{RMSE}}(\operatorname{Donoso}(0.2,0.8,0.2))=0.17$

$\operatorname{Accu}_{\mathrm{RMSE}}(\operatorname{Donoso}(0.7,0.3,0.3))=0.18$

Comparatively, the forecasting performance of the fuzzy collaborative forecasting method is 
$\operatorname{Prec}_{\mathrm{AR}}(\mathrm{FCF}(\operatorname{Donoso}(0.2,0.8,0.2), \operatorname{Donoso}(0.7,0.3,0.3)))=0.48$

$\operatorname{Accu}_{\mathrm{MAE}}(\mathrm{FCF}(\operatorname{Donoso}(0.2,0.8,0.2), \operatorname{Donoso}(0.7,0.3,0.3)))=0.07$

$A c c u_{\text {MAPE }}(\operatorname{FCF}(\operatorname{Donoso}(0.2,0.8,0.2), \operatorname{Donoso}(0.7,0.3,0.3)))=5 \%$

$\operatorname{Accu}_{\mathrm{RMSE}}(\mathrm{FCF}(\operatorname{Donoso}(0.2,0.8,0.2), \operatorname{Donoso}(0.7,0.3,0.3)))=0.10$

Therefore, the quality of collaboration can be evaluated as

$\left.Q o C p_{\mathrm{MPI}, \mathrm{AR}}(\mathrm{FCF}(\operatorname{Donoso}(0.2,0.8,0.2), \operatorname{Donoso}(0.7,0.3,0.3)))\right)=16 \%$.

$\left.Q o C p_{\mathrm{API}, \mathrm{AR}}(\mathrm{FCF}(\operatorname{Donoso}(0.2,0.8,0.2), \operatorname{Donoso}(0.7,0.3,0.3)))\right)=8 \%$.

$\left.Q o C a_{\mathrm{MPI}, \mathrm{MAE}}(\mathrm{FCF}(\operatorname{Donoso}(0.2,0.8,0.2), \operatorname{Donoso}(0.7,0.3,0.3)))\right)=53 \%$.

$\left.Q o C a_{\mathrm{API}, \mathrm{MAE}}(\mathrm{FCF}(\operatorname{Donoso}(0.2,0.8,0.2), \operatorname{Donoso}(0.7,0.3,0.3)))\right)=52 \%$.

$\left.Q o C a_{\mathrm{MPI}, \mathrm{MAPE}}(\mathrm{FCF}(\operatorname{Donoso}(0.2,0.8,0.2), \operatorname{Donoso}(0.7,0.3,0.3)))\right)=44 \%$.

$\left.Q o C a_{\mathrm{API}, \mathrm{MAPE}}(\mathrm{FCF}(\operatorname{Donoso}(0.2,0.8,0.2), \operatorname{Donoso}(0.7,0.3,0.3)))\right)=44 \%$.

$\left.Q o C a_{\text {MPI,RMSE }}(\operatorname{FCF}(\operatorname{Donoso}(0.2,0.8,0.2), \operatorname{Donoso}(0.7,0.3,0.3)))\right)=44 \%$.

$\left.Q o C a_{\mathrm{API}, \mathrm{RMSE}}(\mathrm{FCF}(\operatorname{Donoso}(0.2,0.8,0.2), \operatorname{Donoso}(0.7,0.3,0.3)))\right)=43 \%$.

It is worth noting that the performance of this collaboration model is not as good as expected.

\section{Model 4. FCF(CL1 $\left.\left(o_{1}, s_{1}\right), \operatorname{CL1}\left(o_{2}, s_{2}\right)\right)$}

In this model, the two objects use the same method $\operatorname{CL} 1(o, s)$, but with different values of $o$ and $s$ to predict the unit cost. $\mathrm{CL} 1(o, s)$ is an extension of $\mathrm{WT}(s)$ by considering a nonlinear objective function instead. To make a comparison, the parameter values of the two objects are set to

$$
\begin{aligned}
& \left(o_{1}, s_{1}\right)=(3,0.3) \\
& \left(o_{2}, s_{2}\right)=(2,0.6)
\end{aligned}
$$

The $s$ values are the same with those in the original WT $(s)$ methods. After forecasting the unit cost, the performances of the two objects are evaluated as

$$
\begin{aligned}
& \operatorname{Prec}_{\mathrm{AR}}(\mathrm{CL} 1(3,0.3))=0.56 \\
& \operatorname{Prec}_{\mathrm{AR}}(\mathrm{CL} 1(2,0.6))=1.12 \\
& \operatorname{Accu}_{\mathrm{MAE}}(\mathrm{CL} 1(3,0.3))=0.16 \\
& \operatorname{Accu}_{\mathrm{MAE}}(\mathrm{CL} 1(2,0.6))=0.23 \\
& \operatorname{Accu}_{\mathrm{MAPE}}(\mathrm{CL} 1(3,0.3))=10 \% \\
& \left.\operatorname{Accu}_{\mathrm{MAPE}}(\mathrm{CL} 1(2,0.6))\right)=14 \% \\
& \operatorname{Accu}_{\mathrm{RMSE}}(\mathrm{CL} 1(3,0.3))=0.19 \\
& \operatorname{Accu}_{\mathrm{RMSE}}(\mathrm{CL} 1(2,0.6))=0.30
\end{aligned}
$$

Then, the forecasting performances are compared with those of the linear methods WT $(0.3)$ and WT(0.6). The results are summarized in Table 2.

Table 2. Comparison of the performances of $\operatorname{CL1}(o, s)$ and $\mathrm{WT}(s)$.

\begin{tabular}{ccccc}
\hline & Prec $_{\text {AR }}$ & Accu $_{\text {MAE }}$ & Accu $_{\text {MAPE }}$ & Accu $_{\text {RMSE }}$ \\
\hline WT(0.3) & 0.56 & 0.16 & 0.1 & 0.19 \\
CL1(3, 0.3) & 0.56 & 0.16 & 0.1 & 0.19 \\
WT(0.6) & 1.14 & 0.24 & 0.15 & 0.31 \\
CL1(2, 0.6) & 1.12 & 0.23 & 0.14 & 0.3 \\
\hline
\end{tabular}

Obviously, the use of a nonlinear objective function may change the optimal solution. The quality of collaboration is evaluated as follows: 
$Q o C p_{\mathrm{MPI}, \mathrm{AR}}(\mathrm{FCF}(\mathrm{CL} 1(3,0.3), \operatorname{CL} 1(2,0.6)))=50 \%$.

$Q o C p_{\mathrm{API}, \mathrm{AR}}(\mathrm{FCF}(\mathrm{CL} 1(3,0.3), \mathrm{CL} 1(2,0.6)))=25 \%$.

$Q o C a_{\mathrm{MPI}, \mathrm{MAE}}(\mathrm{FCF}(\mathrm{CL} 1(3,0.3), \mathrm{CL} 1(2,0.6)))=71 \%$.

$Q o C a_{\mathrm{API}, \mathrm{MAE}}(\mathrm{FCF}(\mathrm{CL} 1(3,0.3), \mathrm{CL} 1(2,0.6)))=65 \%$.

$Q o C a_{\mathrm{MPI}, \mathrm{MAPE}}(\mathrm{FCF}(\mathrm{CL} 1(3,0.3), \mathrm{CL} 1(2,0.6)))=67 \%$.

$Q o C a_{\mathrm{API}, \mathrm{MAPE}}(\mathrm{FCF}(\mathrm{CL} 1(3,0.3), \mathrm{CL} 1(2,0.6)))=60 \%$.

$Q o C a_{\mathrm{MPI}, \mathrm{RMSE}}(\mathrm{FCF}(\mathrm{CL} 1(3,0.3), \mathrm{CL} 1(2,0.6)))=66 \%$.

$Q o C a_{\mathrm{API}, \mathrm{RMSE}}(\mathrm{FCF}(\mathrm{CL} 1(3,0.3), \mathrm{CL} 1(2,0.6)))=57 \%$.

Then, the quality of collaboration in $\operatorname{FCF}(\operatorname{CL} 1(3,0.3), \operatorname{CL} 1(2,0.6))$ is compared with that in $\mathrm{FCF}(\mathrm{WT}(0.3)$, WT(0.6)). The results are shown in Table 3.

Table 3. Comparison of FCF(WT(0.3), WT(0.6)) and FCF(CL1(3, 0.3), CL1(2, 0.6)).

\begin{tabular}{ccc}
\hline & FCF(WT(0.3), WT(0.6)) & FCF(CL1 (3, 0.3), CL1 (2, 0.6)) \\
\hline$Q o C p_{\mathrm{MPI}, \mathrm{AR}}$ & $\mathbf{5 4 \%}$ & $50 \%$ \\
$Q o C p_{\mathrm{API}, \mathrm{AR}}$ & $\mathbf{2 9 \%}$ & $25 \%$ \\
$Q o C a_{\mathrm{MPI}, \mathrm{MAE}}$ & $71 \%$ & $71 \%$ \\
$Q o C a_{\mathrm{API}, \mathrm{MAE}}$ & $64 \%$ & $\mathbf{6 5 \%}$ \\
$Q o C a_{\mathrm{MPI}, \mathrm{MAPE}}$ & $67 \%$ & $67 \%$ \\
$Q o C a_{\mathrm{API}, \mathrm{MAPE}}$ & $58 \%$ & $\mathbf{6 0 \%}$ \\
$Q o C a_{\mathrm{MPI}, \mathrm{RMSE}}$ & $52 \%$ & $\mathbf{6 6 \%}$ \\
$Q o C a_{\mathrm{API}, \mathrm{RMSE}}$ & $36 \%$ & $\mathbf{5 7 \%}$ \\
\hline
\end{tabular}

As can be seen from this table, the use of a nonlinear model CL1 $(o, s)$ instead of the linear model $\mathrm{WT}(s)$ can indeed achieve a better quality of collaboration, especially in the forecasting accuracy.

Model 5. FCF(CL2 $\left.\left(o_{1}, d_{1}, m_{1}\right), \operatorname{CL2}\left(o_{2}, d_{2}, m_{2}\right)\right)$

This model assumes that both of the two objects use CL2 $(o, d, m)$, but with different values to predict the unit cost

$$
\begin{aligned}
& \left(o_{1}, d_{1}, m_{1}\right)=(3,0.3,2) \\
& \left(o_{2}, d_{2}, m_{2}\right)=(2,0.5,3)
\end{aligned}
$$

The performances of the two objects are evaluated as

$$
\begin{aligned}
& \operatorname{Prec}_{\mathrm{AR}}(\mathrm{CL} 2(3,0.3,2))=0.48 \\
& \operatorname{Prec}_{\mathrm{AR}}(\mathrm{CL} 2(2,0.5,3))=0.66 \\
& \operatorname{Accu}_{\mathrm{MAE}}(\mathrm{CL} 2(3,0.3,2))=0.16 \\
& A c c u_{\mathrm{MAE}}(\mathrm{CL} 2(2,0.5,3))=0.16 \\
& \operatorname{Accu}_{\mathrm{MAPE}}(\mathrm{CL} 2(3,0.3,2))=10 \% \\
& \left.A c c u_{\mathrm{MAPE}}(\mathrm{CL} 2(2,0.5,3))\right)=10 \% \\
& A c c u_{\mathrm{RMSE}}(\mathrm{CL} 2(3,0.3,2))=0.19 \\
& \operatorname{Accu}_{\mathrm{RMSE}}(\mathrm{CL} 2(2,0.5,3))=0.20
\end{aligned}
$$

Through the collaboration of the two objects, $\operatorname{FCF}(\operatorname{CL} 2(3,0.3,2), \operatorname{CL} 2(2,0.5,3))$ achieves a better forecasting performance:

$\operatorname{Prec}_{\mathrm{AR}}(\mathrm{FCF}(\mathrm{CL} 2(3,0.3,2), \mathrm{CL} 2(2,0.5,3)))=0.35$

$A c c u_{\mathrm{MAE}}(\mathrm{FCF}(\mathrm{CL} 2(3,0.3,2), \mathrm{CL} 2(2,0.5,3)))=0.05$ 
$A c c u_{\text {MAPE }}(\mathrm{FCF}(\mathrm{CL} 2(3,0.3,2), \mathrm{CL} 2(2,0.5,3)))=4 \%$

$A c c u_{\mathrm{RMSE}}(\mathrm{FCF}(\mathrm{CL} 2(3,0.3,2), \mathrm{CL} 2(2,0.5,3)))=0.09$

The quality of collaboration is assessed as follows:

$Q o C p_{\mathrm{MPI}, \mathrm{AR}}(\mathrm{FCF}(\mathrm{CL} 2(3,0.3,2), \mathrm{CL} 2(2,0.5,3)))=46 \%$.

$Q o C p_{\mathrm{API}, \mathrm{AR}}(\mathrm{FCF}(\mathrm{CL} 2(3,0.3,2), \mathrm{CL} 2(2,0.5,3)))=37 \%$.

$Q o C a_{\mathrm{MPI}, \mathrm{MAE}}(\mathrm{FCF}(\mathrm{CL} 2(3,0.3,2), \mathrm{CL} 2(2,0.5,3)))=69 \%$.

$Q o C a_{\mathrm{API}, \mathrm{MAE}}(\mathrm{FCF}(\mathrm{CL} 2(3,0.3,2), \mathrm{CL} 2(2,0.5,3)))=68 \%$.

$Q o C a_{\text {MPI,MAPE }}(\mathrm{FCF}(\mathrm{CL} 2(3,0.3,2), \mathrm{CL} 2(2,0.5,3)))=63 \%$.

$Q o C a_{\text {API,MAPE }}(\operatorname{FCF}(\mathrm{CL} 2(3,0.3,2), \mathrm{CL} 2(2,0.5,3)))=63 \%$.

$Q o C a_{\mathrm{MPI}, \mathrm{RMSE}}(\mathrm{FCF}(\mathrm{CL} 2(3,0.3,2), \mathrm{CL} 2(2,0.5,3)))=54 \%$.

$Q o C a_{\mathrm{API}, \mathrm{RMSE}}(\mathrm{FCF}(\mathrm{CL} 2(3,0.3,2), \mathrm{CL} 2(2,0.5,3)))=53 \%$.

\section{Model 6. FCF $\left(\operatorname{CL1}\left(o_{1}, s_{1}\right), \operatorname{CL2}\left(o_{2}, d_{2}, m_{2}\right)\right)$}

In this model, one of the two objects uses $\operatorname{CL1}(o, s)$, and the other uses CL2 $(o, d, m)$.

$\left(o_{1}, s_{1}\right)=(3,0.3)$

$\left(o_{2}, d_{2}, m_{2}\right)=(2,0.5,3)$

The forecasting performance of $\mathrm{FCF}(\mathrm{CL} 1(3,0.3), \mathrm{CL} 2(2,0.5,3))$ is evaluated as

$\operatorname{Prec}_{\mathrm{AR}}(\mathrm{FCF}(\mathrm{CL} 1(3,0.3), \mathrm{CL} 2(2,0.5,3)))=0.39$

$A c c u_{\mathrm{MAE}}(\mathrm{FCF}(\mathrm{CL} 1(3,0.3), \mathrm{CL} 2(2,0.5,3)))=0.07$

$A c c u_{\text {MAPE }}(\mathrm{FCF}(\mathrm{CL} 1(3,0.3), \mathrm{CL} 2(2,0.5,3)))=5 \%$

$A c c u_{\mathrm{RMSE}}(\mathrm{FCF}(\mathrm{CL} 1(3,0.3), \mathrm{CL} 2(2,0.5,3)))=0.11$

The quality of collaboration is assessed as follows:

$Q o C p_{\mathrm{MPI}, \mathrm{AR}}(\mathrm{FCF}(\mathrm{CL} 1(3,0.3), \mathrm{CL} 2(2,0.5,3)))=41 \%$.

$Q o C p_{\mathrm{API}, \mathrm{AR}}(\mathrm{FCF}(\mathrm{CL} 1(3,0.3), \mathrm{CL} 2(2,0.5,3)))=30 \%$.

$Q o C a_{\mathrm{MPI}, \mathrm{MAE}}(\mathrm{FCF}(\mathrm{CL} 1(3,0.3), \mathrm{CL} 2(2,0.5,3)))=59 \%$.

$Q o C a_{\mathrm{API}, \mathrm{MAE}}(\mathrm{FCF}(\mathrm{CL} 1(3,0.3), \mathrm{CL} 2(2,0.5,3)))=59 \%$.

$Q o C a_{\text {MPI,MAPE }}(\mathrm{FCF}(\mathrm{CL} 1(3,0.3), \mathrm{CL} 2(2,0.5,3)))=52 \%$.

$Q o C a_{\text {API,MAPE }}(\mathrm{FCF}(\mathrm{CL} 1(3,0.3), \mathrm{CL} 2(2,0.5,3)))=52 \%$.

$Q o C a_{\text {MPI,RMSE }}(\mathrm{FCF}(\mathrm{CL} 1(3,0.3), \mathrm{CL} 2(2,0.5,3)))=46 \%$.

$Q o C a_{\mathrm{API}, \mathrm{RMSE}}(\mathrm{FCF}(\mathrm{CL} 1(3,0.3), \mathrm{CL} 2(2,0.5,3)))=45 \%$.

\subsection{Comparison of the Performances of the Fuzzy Collaborative Forecasting Models}

In this section, the performances of the fuzzy collaborative forecasting models are compared. First, the forecasting accuracy considering the average range of forecasts, the performances of different models are compared in Figure 2. Obviously, in terms of the forecasting accuracy, $\operatorname{FCF}(\mathrm{CL} 2(3,0.3,2)$, CL2 $(2,0.5,3))$ is much better than the other models. However, this is partly because the settings of the parameters in the models are different and subjective. In order to confirm the effects of different models for the forecasting accuracy, the quality of collaboration, especially $Q o C p_{\mathrm{API}, \mathrm{AR}}$, is considered to be a better indicator. The comparison results are shown in Figure 3. As can be seen from this figure, $\mathrm{FCF}(\mathrm{CL} 2(3,0.3,2), \mathrm{CL} 2(2,0.5,3))$ is indeed the most precise fuzzy collaborative forecasting model in this case. 
Figure 2. The forecasting accuracy of the fuzzy collaborative forecasting models.

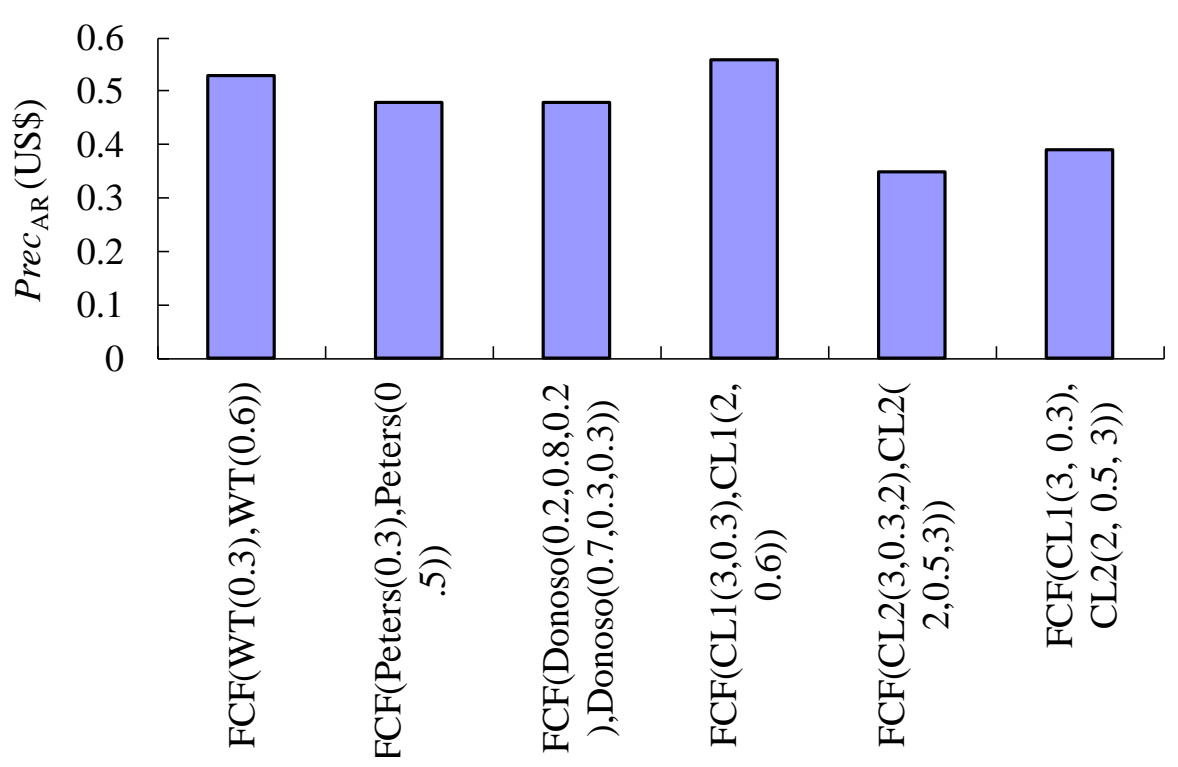

Secondly, in order to compare the forecasting accuracy of the models, three indicators-MAE, MAPE, and RMSE are considered. The comparison results in the three indicators are shown in Figures $4-6$, respectively. For all indicators of the forecasting accuracy, $\operatorname{FCF}(\operatorname{CL} 2(3,0.3,2), \operatorname{CL} 2(2,0.5,3))$ is the best fuzzy collaborative forecasting model. Next, the quality of collaboration is compared, and the results are shown in Figure 7. The quality of collaboration in $\operatorname{FCF}(\operatorname{CL} 1(3,0.3), \operatorname{CL} 1(2,0.6))$ is the best if RMSE is taken into account, and FCF(CL2 $(3,0.3,2)$, CL2 $(2,0.5,3))$ achieves the highest quality of collaboration if MAE or MAPE is considered.

Figure 3. The quality of collaboration of the fuzzy collaborative forecasting models.

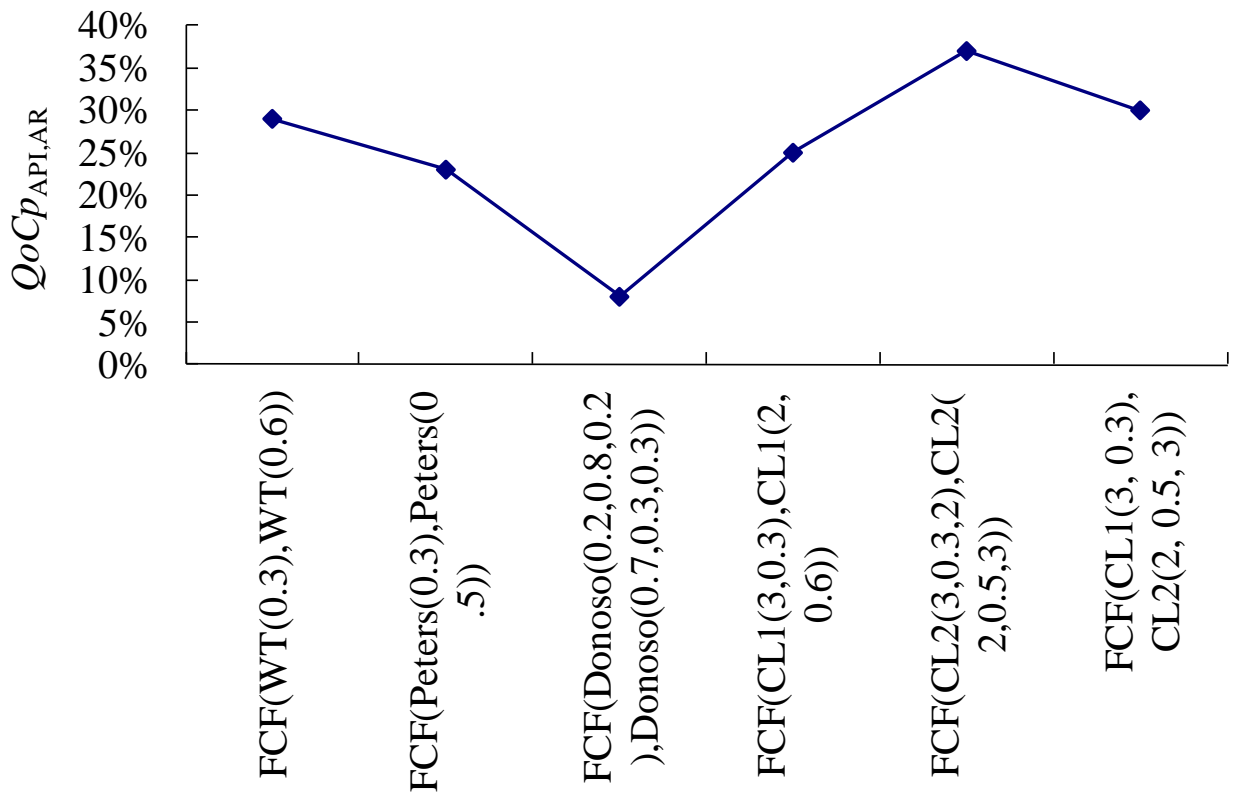


Figure 4. The forecasting accuracy (MAE) of the fuzzy collaborative forecasting models.

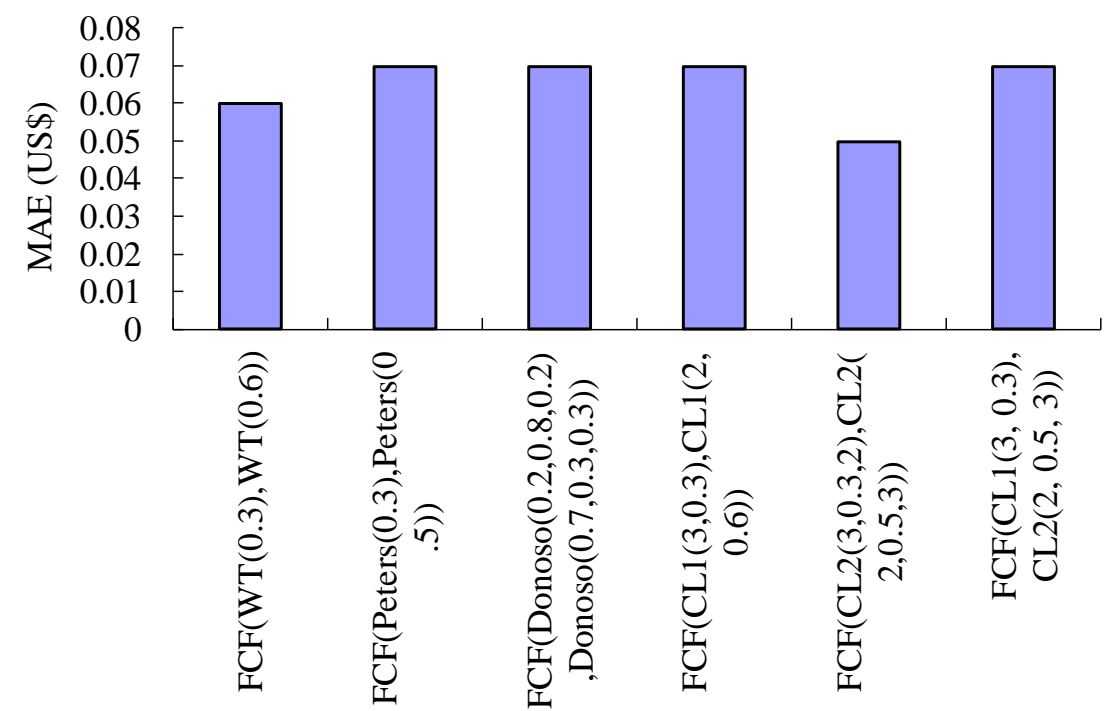

Figure 5. The forecasting accuracy (MAPE) of the fuzzy collaborative forecasting models.

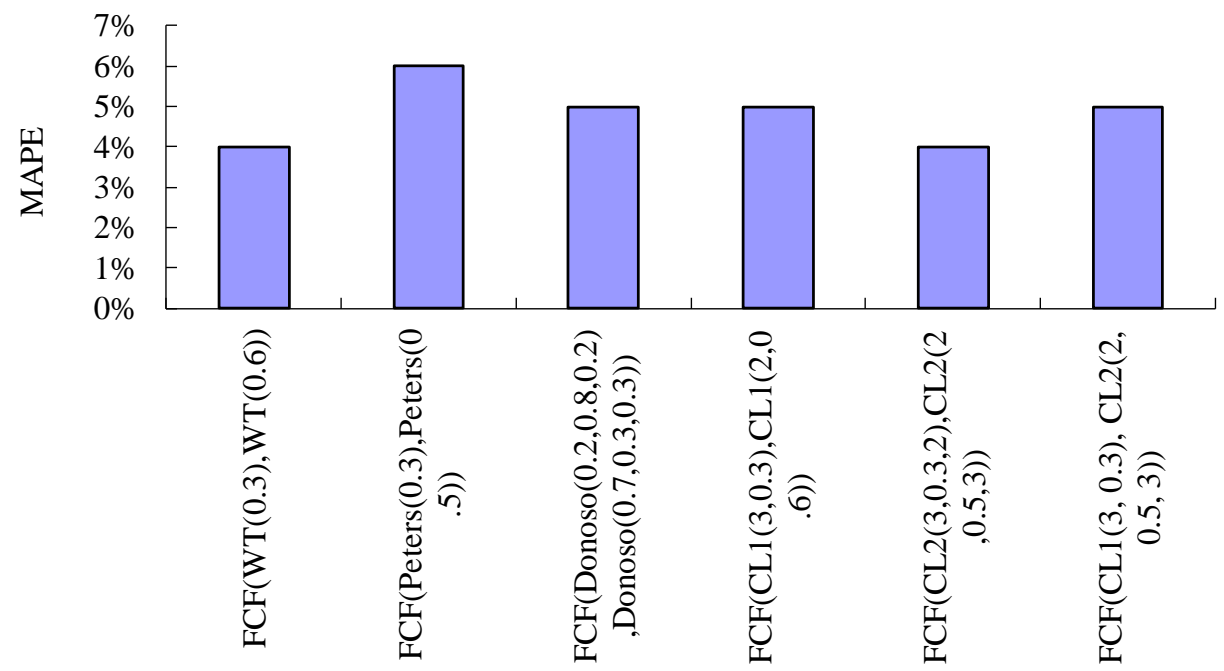

Figure 6. The forecasting accuracy (RMSE) of the fuzzy collaborative forecasting models.

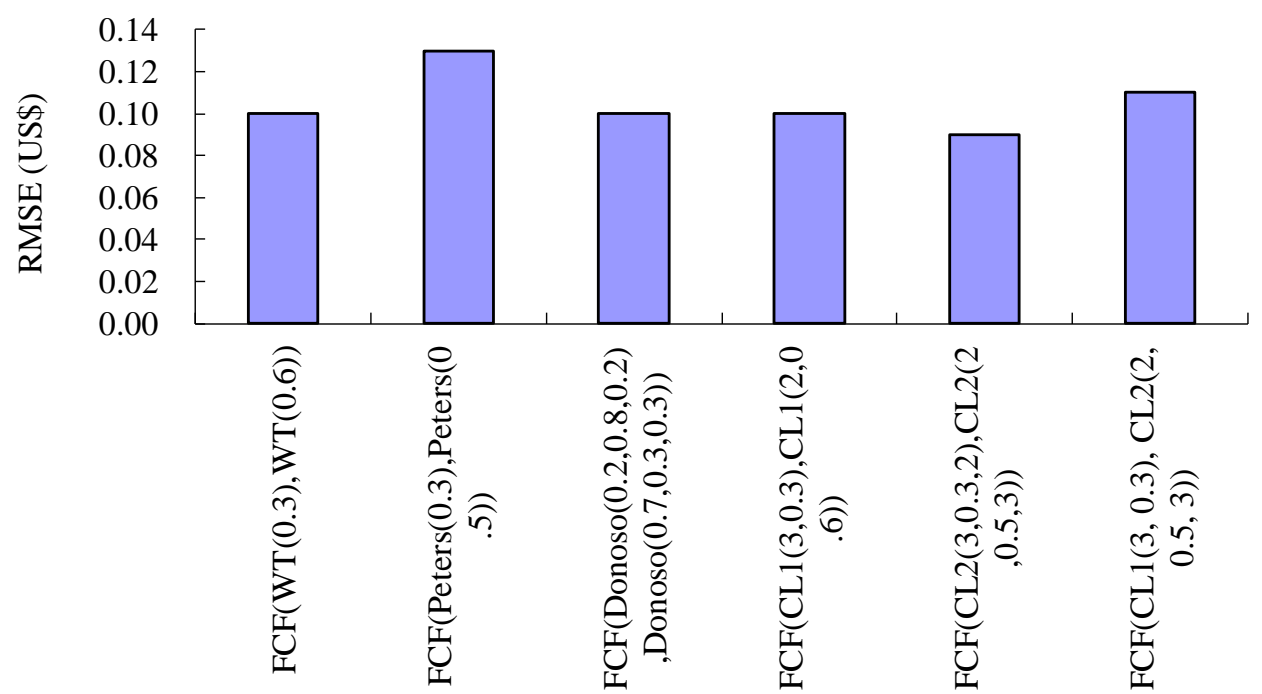


Figure 7. The quality of collaboration of the fuzzy collaborative forecasting models.

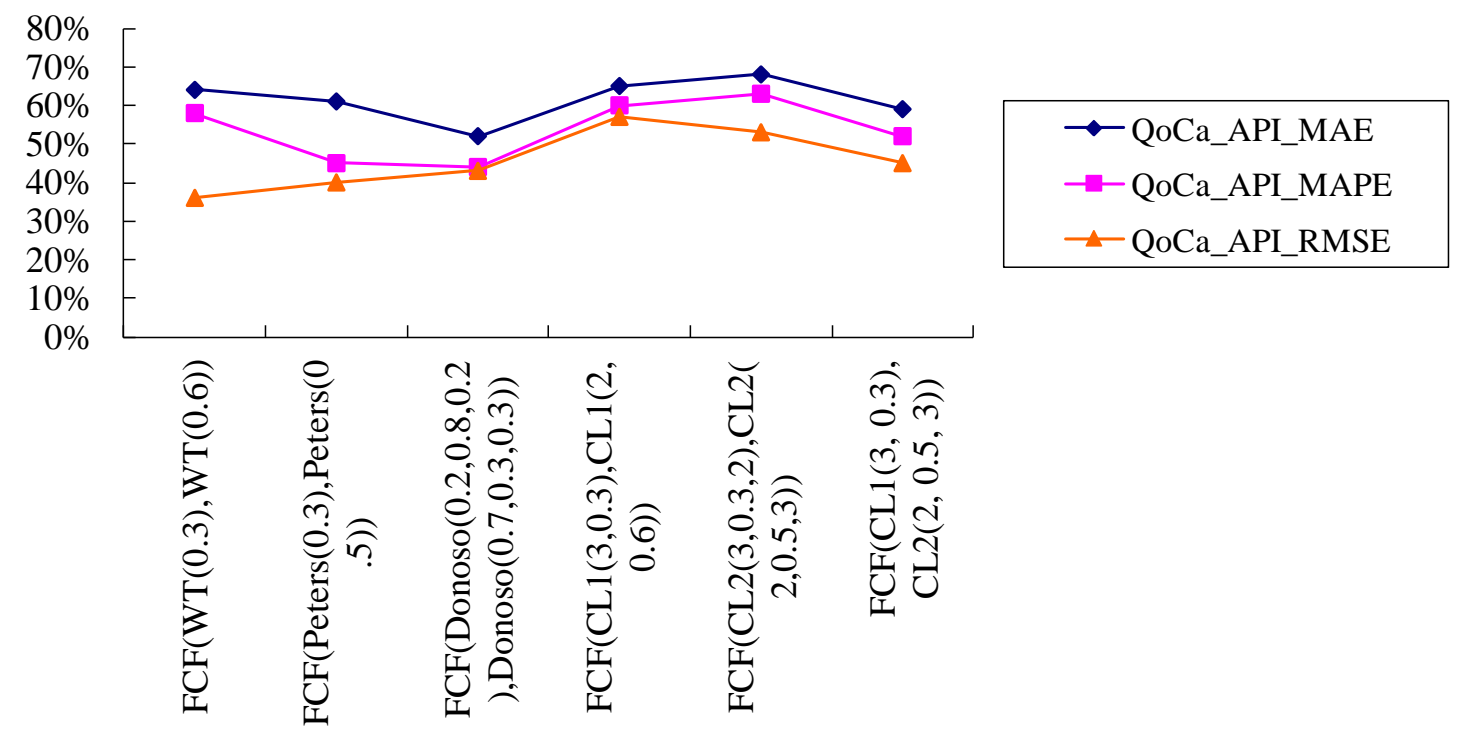

\section{Conclusions}

Forecasting the unit cost of every product type in a factory is an important task. After the unit cost of every product type in a factory is accurately forecasted, several managerial goals (including pricing, cost down projecting, capacity planning, ordering decision support, and guiding subsequent operations) can be simultaneously achieved. However, it is not easy to deal with uncertainty in the unit cost. This paper presents some fuzzy collaborative forecasting models based on a few well-known fuzzy linear regression methods to predict the unit cost of a product. An example is used to illustrate the applicability of the proposed methodology. According to the experimental results,

(1) The effectiveness of the unit cost forecasting was greatly improved through the collaboration of the experts, especially when using $\mathrm{FCF}\left(\mathrm{CL} 2\left(o_{1}, d_{1}, m_{1}\right)\right.$, CL2 $\left.\left(o_{2}, d_{2}, m_{2}\right)\right)$.

(2) With respect to the quality of collaboration on the forecasting precision, only one performance measure is proposed and the proposed performance measure can effectively compare the differences among the models.

(3) With respect to the forecasting accuracy on the forecasting accuracy among the performance measures, the one that considers MAPE can effectively compare the differences among the models.

The contribution of this study includes the following:

(1) Six fuzzy collaborative forecasting models for the unit cost forecasting are investigated. From this, the most effective one can be identified.

(2) More performance measures on the quality of collaboration have been proposed.

\section{Acknowledgements}

This work is partially supported by National Science Council of Taiwan. 


\section{References}

1. Chen, T. A fuzzy-neural knowledge-based system for job completion time prediction and internal due date assignment in a wafer fabrication plant. Int. J. Sys. Sci. 2009, 40, 889-902.

2. Chen, T. A hybrid fuzzy and neural approach with virtual experts and partial consensus for DRAM price forecasting. Int. J. Innov. Comput. Inf. Control 2012, 8, 583-598.

3. Chen, T. An online collaborative semiconductor yield forecasting system. Expert Sys. Appl. 2009, $36,5830-5843$.

4. Chen, T. An application of fuzzy collaborative intelligence to unit cost forecasting with partial data access by security consideration. Int. J. Technol. Intel. Plan. 2011, 7, 201-214.

5. Chen, T. Applying a fuzzy and neural approach for forecasting the foreign exchange rate. Int. J. Fuzzy Sys. Appl. 2011, 1, 36-48.

6. Chen, T. Applying the hybrid fuzzy c means-back propagation network approach to forecast the effective cost per die of a semiconductor product. Comput. Ind. Eng. 2011, 61, 752-759.

7. Chen, T. Some linear fuzzy collaborative forecasting models for semiconductor unit cost forecasting. Int. J. of Fuzzy Sys. Appl. 2012, in press.

8. Chen, T.; Lin, Y.C. A fuzzy-neural system incorporating unequally important expert opinions for semiconductor yield forecasting. Int. J. Uncertain. Fuzziness Knowl. Based Syst. 2008, 16, 35-58.

9. Chen, T.; Lin, C.W.; Wang, Y.C. A fuzzy collaborative forecasting approach for WIP level estimation in a wafer fabrication factory. Appl. Math. Inf. Sci. 2012, in press.

10. Chen, T.; Wang, Y.C. A fuzzy-neural approach for global $\mathrm{CO}_{2}$ concentration forecasting. Intel. Data Anal. 2011, 15, 763-777.

11. Chen, T.; Wang, Y.C. A hybrid fuzzy and neural approach for forecasting the book-to-bill ratio in the semiconductor manufacturing industry. Int. J. Adv. Manuf. Technol. 2011, 54, 377-389.

12. Pedrycz, W. Collaborative architectures of fuzzy modeling. Lect. Notes Comput. Sci. 2008, 5050, 117-139.

13. Pedrycz, W. Collaborative fuzzy clustering. Pattern Recognit. Lett. 2002, 23, 1675-1686.

14. Pedrycz, W.; Rai, P. A multifaceted perspective at data analysis: A study in collaborative intelligent agents. IEEE Trans. Syst., Man. Cybern., Part B: Cybern. 2008, 38, 1062-1072

15. Carnes, R. Long-term cost of ownership: beyond purchase price. In Proceedings of 1991 IEEE/SEMI International Semiconductor Science Symposium, Burlingame, CA, USA, 20-22 May 1991; pp. 39-43.

16. Wood, S.C. Cost and cycle time performance of fabs based on integrated single-wafer processing. IEEE Trans. Semi. Manuf. 1997, 10, 98-111.

17. Pfitzner, L.; Benesch, N.; Öchsner, R.; Schmidt, C.; Schneider, C.; Tschaftary, T.; Trunk, R.; Dudenhausen, H.M. Cost reduction strategies for wafer expenditure. Microelectr. Eng. 2001, 56, 61-71.

18. Shai, O.; Reich, Y. Infused design I. Theory. Res. Eng. Design Res. 2004, 15, 93-107.

19. Shai, O.; Reich, Y. Infused design II. Practice. Res. Eng. Design Res. 2004, 15, 108-121. 
20. Büyüközkan, G.; Vardaloglu, Z. Analyzing of Collaborative Planning, Forecasting and Replenishment Approachusing Fuzzy Cognitive Map. In Proceeding of 2009 International Conference on Computers and Industrial Engineering, University of Technology of Troyes, France, 6-8 July 2009; pp. 1751-1756.

21. Büyüközkan, G.; Feyzioglu, O.; Vardaloglu, Z. Analyzing CPFR supporting factors with fuzzy cognitive map approach. World Academy Sci. Eng. Technol. 2009, 31, 412-417.

22. Poler, R.; Hernandez, J.E.; Mula, J.; Lario, F.C. Collaborative forecasting in networked manufacturing enterprises. J. Manuf. Technol. Manag. 2008, 19, 514-528.

23. Ostrosi, E.; Haxhiaj, L.; Fukuda, S. Fuzzy modelling of consensus during design conflict resolution. Res. Eng. Design 2012, 23(1), 53-70.

24. Cheikhrouhou, N.; Marmier, F.; Ayadi, O.; Wieser, P. A collaborative demand forecasting process with event-based fuzzy judgements. Comput. Ind. Eng. 2011, 61, 409-421.

25. Gruber, H. Learning and Strategic Product Innovation: Theory and Evidence for the Semiconductor Industry; Elsevier: Amsterdam, the Netherlands, 1994.

26. Chen, T. A fuzzy back propagation network for output time prediction in a wafer fab. Appl. Soft Comput. 2003, 2, 211-222.

27. Chen, T. A hybrid fuzzy and neural approach for evaluating the cost competitiveness of a semiconductor product. Int. J. Technol. Intel. Plan. 2010, 6, 373-386.

28. Chen, T. A SOM-FBPN-ensemble approach with error feedback to adjust classification for wafer-lot completion time prediction. Int. J. Adv. Manuf. Technol. 2008, 37, 782-792.

29. Chen, T.; Wang, M.J.J. A fuzzy set approach for yield learning modeling in wafer manufacturing. IEEE Trans. Semicond. Manuf. 1999, 12, 252-258.

30. Tanaka, H.; Watada, J. Possibilistic linear systems and their application to the linear regression model. Fuzzy Sets Syst. 1988, 272, 275-289.

31. Peters, G. Fuzzy linear regression with fuzzy intervals. Fuzzy Sets Syst. 1994, 63, 45-55.

32. Donoso, S.; Marin, N.; Vila, M.A. Quadratic programming models for fuzzy regression. In Proceedings of International Conference on Mathematical and Statistical Modeling in Honor of Enrique Castillo, Ciudad Real, Spain, 28-30 June 2006.

33. Liu, X. Parameterized defuzzification with maximum entropy weighting function — another view of the weighting function expectation method. Math. Com. Mod. 2007, 45, 177-188.

34. Eraslan, E. The estimation of product standard time by artificial neural networks in the molding industry. Math. Probl. Eng. 2009, article ID 527452.

(C) 2012 by the authors; licensee MDPI, Basel, Switzerland. This article is an open access article distributed under the terms and conditions of the Creative Commons Attribution license (http://creativecommons.org/licenses/by/3.0/). 